Geenen R. Lack of understanding in fibromyalgia and rheumatoid arthritis: the IIIness Invalidation Inventory (3*I). Ann Rheum Dis 2010;69:1990-5. Disclosure of Interest: None declared

DOI: 10.1136/annrheumdis-2017-eular.2472

\section{OP0143-HPR DISABILITY IN THE FEET RELATED TO PARTICIPATION IN DAILY LIFE IN PATIENTS WITH EARLY RA - AN INTERVIEW STUDY IN THE SWEDISH TIRA PROJECT}

M. Björk ${ }^{1,2}$, I. Thyberg ${ }^{3}$, E. Valtersson ${ }^{4}$, G. Östlund ${ }^{5}$, B. Stenström ${ }^{3}$, A. Sverker ${ }^{6} .{ }^{1}$ Department of Social and Welfare Studies, Linköping University, Norrköping; ${ }^{2}$ Rheumatology clinic, Linköping university hospital; ${ }^{3}$ Department of Rheumatology: ${ }^{4}$ Department of Activity and Health and Department of Medical and Health Sciences, Linköping University, Linköping; ${ }^{5}$ School of Health Care and Social Welfare, Mälardalen University, Eskilstuna; ${ }^{6}$ Department of Activity and Health, Department of Rehabilitation Medicine, Department of Social and Welfare studies, Linköping university, Linköping, Sweden

Background: Pain, stiffness and deformity of the feet are related to reduced mobility and participation restrictions in daily activities in patients with established rheumatoid arthritis (RA). The new biological medications are effective and reduce disease activity, but not disability to the same extent. Foot problems are assumed to be related to participation restrictions also in patients with early RA, diagnosed after the introduction of biological medications, hindering for example physical activity. Hence, there is a need for more knowledge about foot problems in order to identify possible needs for rehabilitative interventions.

Objectives: To explore disability related to foot problems in women and men with early rheumatoid arthritis and its relation to participation in daily life.

Methods: 59 patients (58\% women, 20-63 years) with early RA were interviewed about participation dilemmas in daily life related to RA, using Critical Incident Technique. The interviews were audio-recorded and transcribed. Data related to foot problems were extracted and analysed thematically. A research partner with RA validated the retrieved categories. The study was approved by the Regional Ethics Committee.

Results: More than $2 / 3$ of the patients mentioned that they had participation restrictions related to foot problems. The analysis revealed 5 categories concerning foot problems and the relation to participation restrictions: 1) foot problems as an early indicator of the disease, 2) hindrance in managing the daily routine and house hold activities, 3) struggling to be mobile, 4) difficulties in doing a god job at work and 5) difficulties in participating in recreation and leisure activities. Both women and men shared many experiences, as difficulties to be physically active. Several women expressed difficulties to use the shoes they wanted. Being able to move on uneven ground in, for example, the forest was something that many men expressed as difficult.

Conclusions: Patients with early RA with access to effective medications and multi professional interventions based on their individual needs still experience a wide range of foot related disability in major life arenas as work, in the household and during leisure time. This indicates a need to pay attention also in today's early RA patients to foot problems in the multi professional rehabilitation to prevent further disabilities and enable physical activity for men and women with RA.

Disclosure of Interest: None declared

DOI: 10.1136/annrheumdis-2017-eular.3294

\section{OP0144-HPR "IT CAN'T BE ZERO": A QUALITATIVE STUDY OF PATIENTS' PERSPECTIVE ON PATIENT GLOBAL ASSESSMENT IN RHEUMATOID ARTHRITIS}

M. Henriques ${ }^{1}$, C. Duarte ${ }^{1,2}$, M. Ndosi ${ }^{3}$, A. Marques ${ }^{2}$, J.A.P. da Silva ${ }^{1,2}$, R.J.O. Ferreira 2,4 ${ }^{1}$ Faculdade de Medicina da Universidade de Coimbra; ${ }^{2}$ Centro Hospitalar e Universitário de Coimbra, Coimbra, Portugal; ${ }^{3}$ University of the West of England, Bristol, United Kingdom; ${ }^{4}$ UICISA:E, ESEnfC, Coimbra, Portugal

Background: Patient Global Assessment (PGA) plays an important role in disease activity assessment and treatment decisions in rheumatoid arthritis (RA). However, the meaning of PGA is open to patient interpretation and this may affect the validity and reliability of clinical assessments.

Objectives: We aimed to explore: (i) patients' perspective on PGA and its different formulations (ii) how patients' perspective may be improved by a brief explanation from a health care professional (HCP).

Methods: This was a qualitative study including consecutive patients with RA attending a day hospital and an outpatient department of a university hospital in Portugal. Data collection included 4 focus-groups (FGD) and 3 individual interviews to determine patients' perspectives. To help the discussions, patients completed 3 different PGA formulations consecutively and then a HCP explained what information was expected to inform their PGA. The 3 PGA formulations and their implications were then discussed between the patient and the HCP. Data from the FGDs and the interviews were transcribed verbatim and inductive content analysis was undertaken by two independent researchers. Data were coded and categorised in themes, which were agreed upon with patients, HCP and patient research partners.

Results: Fourteen patients (12 women) with RA participated. Their age ranged from 49 to 72 years, disease duration 4 to 30 years and 11 were on biologic DMARDs. Four main themes emerged (Figure 1): (1) The purpose of PGA. Some patients did not know whether PGA affects their treatment decisions in the same way as the objective measures do: "if the answer is not in somehow according to the exams we make (...) obviously they might ignore me". Some believed that PGA was only used for research purposes. (2) The meaning of PGA. Pain was by far the main meaning of PGA, but also fatigue, function and other dimensions including RA sequelae; (3) Measurement difficulties. Many of these difficulties arose from the presentation of the three different PGA formulations, anchor points and their presentations: "I always think that 100 is great: you feel $100 \%$ ", "Usually the scale is 0 to 10, here I can see 0 to 100": "Usually it has the numbers, I answer 2, it's not like a straight line like this one"; "Today is different (...) when they ask the last week, we have to go back in time and the pain isn't the same anymore". Also cultural issues and the subjectivity of the concept were expressed: "We, the patients, can't really assess the intensity of the pain, what could be a 9 for her, for me it might be a 5"; "I can never answer 0, because I always have something that affects me". (4) Clarification from a HCP as a key factor for global understanding: ["Sometimes I just give a random number. (...) now maybe I will think more carefully and try to be as accurate as possible".

Figure 1. Main themes of Patients' perspective of PGA

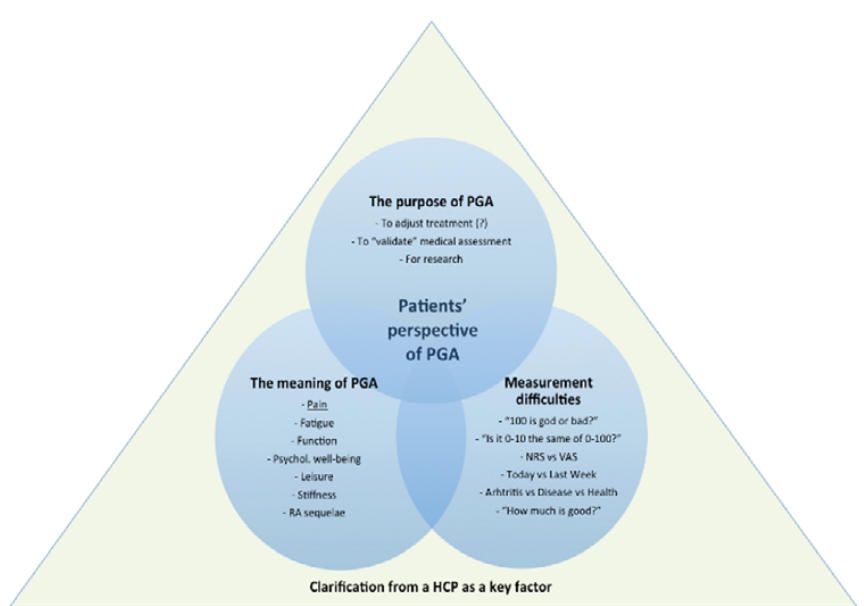

Conclusions: Our results suggest that patients' interpretation of PGA is diverse and may reflect different symptoms such as pain or psychological well-being and comorbidities. Standardization of PGA is warranted and dedicated patient debriefing is likely to improve the reliability of this assessment.

Disclosure of Interest: None declared

DOI: 10.1136/annrheumdis-2017-eular.6214

\section{OP0145-HPR RHEUMATOID ARTHRITIS PATIENTS' SUPPORT NEEDS REGARDING MEDICATION USE AND THEIR PERSPECTIVES ON THE APPLICABILITY OF EHEALTH INTERVENTIONS TO ADDRESS THOSE NEEDS: A FOCUS GROUP STUDY}

E. Mathijssen ${ }^{1}$, J. Vriezekolk ${ }^{1}$, A. Eijsbouts ${ }^{1}$, B. van den Bemt ${ }^{1,2}$

${ }^{1}$ Rheumatology; ${ }^{2}$ Pharmacy, Sint Maartenskliniek, Nijmegen, Netherlands

Background: Patients with rheumatoid arthritis (RA) encounter various problems with their medication use, including poor knowledge about disease-modifying antirheumatic drugs (DMARDs) ${ }^{1}$, concerns about potential adverse consequences of their medication use $\mathrm{s}^{2}$ and struggles with opening the medication's packaging ${ }^{3}$. Additional support might decrease those problems by targeting RA patients with (eHealth) interventions that address their needs. To date, no studies have explored RA patients' support needs regarding medication use from their own perspectives, and it remains largely unknown if, and to what extent, they perceive a need for eHealth interventions.

Objectives: The objective of this study was twofold: 1) to explore RA patients support needs regarding medication use; and 2) to gain insight into their perspectives on the applicability of eHealth interventions to address those needs. Methods: Three focus groups with 28 RA patients (mean age: 65 years, mean disease duration: 19 years) were conducted. All focus groups were audiorecorded and subsequently transcribed verbatim. Two researchers independently conducted an inductive, thematic analysis on the transcripts.

Results: Three themes that described RA patients' support needs regarding medication use were identified: 1) Informational support; 2) Practical support; and 3) Emotional and behavioral support. Informational support refers to the provision of knowledge and facts, including advice, suggestions and feedback from healthcare providers. Practical support includes the strengthening of technical skills (e.g. administering subcutaneous injections), as well as the provision of goods and services. Emotional and behavioral support refers to the interventions enabling RA patients to better cope with their medication use. Their perspectives on the applicability of eHealth interventions to address those needs were also identified. RA patients recognized potential advantages of eHealth interventions, such as being less time consuming and easily accessible. However, concerns 